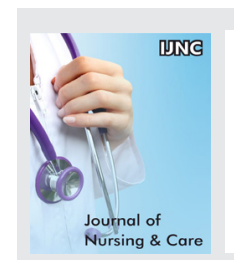

\title{
Is complementary therapy (Vitamin D) effective among Psychiatric disorder? (Depression)?
}

\author{
Qusai Mohammed Harahsheh* \\ School of Nursing, The Hashemite University, Jordan
}

*Corresponding author: Qusai Mohammed Harahsheh, School of Nursing, The Hashemite University, Jordan.
Received Date: March 03, 2019

Published Date: April 18, 2019

Keywords: Complementary therapy; Psychiatric disorder; Depression; Conventional therapy; Vitamin D; Medication

\section{Literature Review}

The relationship between vitamin $\mathrm{D}$ and depression was clarified in many studies, some of this studies shown that there is a strong relationship between vitamin $\mathrm{D}$ and depression and shown that positive effect of vitamin $\mathrm{D}$ among patient with depressive disorder such as decreasing depressive symptoms like worthless, hurt restless, hopeless and feeling empty and cost effective and other positive effects comparing with antidepressants medication. On the other hand few studies shown that there is no relationship between vitamin $\mathrm{D}$ and depressive disorder, and it's just improve the bone tissue with calcium assistance. On this literature review the current author will clarify many articles related to the relationship between vitamin $\mathrm{D}$ and the depressive disorder. Studies found positive effect of vitamin D on Depressive disorder many studies shown positive effect of vitamin D on depressive disorder and many studies shown that there is a relationship between decreasing vitamin $\mathrm{D}$ and increasing depressive symptoms severity(Jisheng Zhane et al 2014) found that the people with low serum of vitamin D has a higher severity depressive symptoms compared with people with normal vitamin D level, on the same time in this experimental article the author use vitamin D supplementation for group of people with severe depressive symptoms within specific period of time and concluded that there is a positive effect in decreasing the severity of symptoms (JishengZhane., et al 2014), moreover the smart point on this article was using the vitamin D supplementation just in winter to avoid important external factors like seasonal factors and sun light strength, on same time the author linked between the chronic diseases which prevent people spending time out door (under sun light) and vitamin D deficiency which may increase the severity of depressive symptoms which reflect the 2 nd reason to choose winter season.

Furthermore, an experimental study done in summer 2009 for 44 healthy student given vitamin D supplementation for 5 days resulting on improving their mood in that period compared with pre supplementation status by using specific tool after and before the experiment [6].Moreover [6] conclude that the higher level of vitamin D in human body has strong relationship with preventing depression.

Moreover a study done in U.S. for 18875 young adults population to link between the concentration of serum vitamin D and depression, by using specific tool for assessment (Diagnostic interview schedule), the sample age was 15-39 years old, they estimate an odd ratio after analyzing the data for vitamin D deficiency and having depression, compared with persons which have normal vitamin D value [7]. On the same topic [7] shown many characteristic which considered as a higher provenance of vitamin D deficiency, this characteristic are below poverty people, female gender, persons which didn't get supplements, non-Hispanic, black people higher BMI people, west regions and south regions European cities and people who have at least one depressive episode, all of characteristic have $\leq 50$ mole/liter, vitamin D serum which mean vitamin D deficiency, this number looked very low compared with 75 mole/liter of serum vitamin D within other people.

The most important result of [7] articles that early diagnoses and actions for vitamin D deficiency and depression have important positive consequences amount people health. Moreover photo 
therapy may use for depression treatment, (shipowick et al 2009) make an experimental studies for six patient of depression by give vitamin D 5000 IE/day for three participant and the other three patient staying from 3-6 hours under the sum light in specific time of the day, all of them shown good consequences.

\section{Studies shown that negative relationship between depression and vitamin $D$}

Actually there is little studies found no relationship between vitamin D and depression, a study in UAE in 2013 for 141 employees from different majors in Abu Dhabi shown that the effect of sun exposure on depression may come from the life style and the routine daily activity then lead to depression which lead to isolation and staying at home which resulting on prevent exposure to sun light (Al-Anouti., et al 2013).

On the other hand, many studies didn't mention vitamin D deficiency as a cause of depression or vitamin D may use as a type of complementary therapy for depressed patient, (Rashid and Heieder, 2008) study consider the childbirth, economical status, work issue, natural tragedies, menopause age, social dysfunction, religion, spiritual issues, all of them considered as depression causes, on the other hand they didn't mentions anything related to vitamin D or vitamin D deficiency to be more specific.Moreover, the chines study for chines population in 2009 which focused in the elderly and middle age people to study the relationship between 25-hydroxyvitamin D and depressive symptoms conclude that there is no relationship between vitamin D and depression (pan et al 2009).Moreover, European study worked on the relationship between the neuropsychological function and the seven of 25-hydroxlvitamin D levels and parathyroid hormone in 206 shown that there is no relationship between vitamin $\mathrm{D}$ and depression.

\section{Summary and Conclusion}

By science growing up the complementary therapy found vitamin D as a therapy for depressed patients, especially when depression considered as worldwide diseases. Most of studies found that depression symptom has positive co-relation between vitamin $\mathrm{D}$ deficiency and found that vitamin $\mathrm{D}$ supplementation is very useful as complementary therapy for depressed patients, studies preferred vitamin D more than medication because it has less side effect and its more economic, furthermore early vitamin D supplementation has positive consequences to prevent depression, on the other hand photo therapy may has the same effect of vitamin D supplementation. Little studies shown that no relationship between vitamin D and depression and one of them didn't clarify the co-relation between the sun exposure and depression or which become first.

\section{Recommendation}

On my opinion there is many consideration must add before any admission in psychiatric department such as serum vitamin D test, family history about vitamin D deficiency and early osteoporosis, bone density, region wither, place of patient live, type of work time at night or day duty and work environment outside office or inside office, all of them must take briefly and specifically. After reading and analyzing large number of studies related to vitamin D and depression, the current author advocate to prescribe vitamin D supplementation for depressed patient and test the serum of vitamin D for depressed people especially and healthy people to promote their health statues.

\section{Acknowledgement}

None.

\section{References}

1. World Health Organization (2008) Mental Health Gap action Programmed: Scaling up Care for Mental, Neurological, and Substance Use Disorders, WHO, Geneva, Switzerland.

2. Hyman S, Chisholm D, Kessler R, Patel V, Whiteform H (2006) Mental disorders. In: Jamison DT, Breman JG, Measham AR, Alleyne G, Claeson M, et al. (Eds.), Disease control Prioritys in Developing Countries $\left(2^{\text {nd }}\right.$ edn), 1 Oxford University Press, New Youk, USA, pp. 605-626.

3. Lopz AD, Mathers CD, Ezzati M, Jamison DT, Murray CJ (2006) Global and regional burden of diseases and risk factor, 2001: systematic analysis of population health data. Lancet 367(9524): 1747-1757.

4. Jordanes (2012) The Origin and Deeds of the GothlMierow CC. Princeton University Press, Princeton, NJ, USA, pp. 19-21.

5. Young SN (2009) Has the time come for clinical trials on the antidepressant effect of vitamin D? J Psychiatry Neurosis 34(3).

6. Kauffman J (2009) Benefits of Vitamin D Supplementation. Journal of American Physician and Surgeons 14(2).

7. Ganji V, Milone C, Cody M, McCarty F, Wang C (2010) Serum vitamin D concentrations are related to depression in young adult US population: the Third National Health and Nutrition Examination Survey. International Archives of Medicine 3(29): 1-8.

8. Al Khatib A, Rawashdeh W (2014) The Relationship between Vitamin D Deficiency with depression and Addiction. European Scientific Journal 10(24): 131-142.

9. http://www.who.int/topics/depression/en/

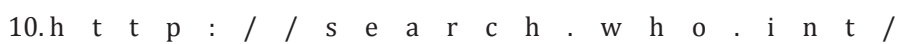
search?q=complementary + therapy\&ie $=u t f 8 \&$ site $=$ who\&client $=$ _ e n_r \& proxystylesheet $=_{-}$e n $\_$r \& output $=x_{m l} l_{-}$no $_{-}$ $\mathrm{dtd} \&$ oe=utf8\&getfields=doctype

11. Zhang J, Zhang P, Ni X, Bao B, Huang C, et al. (2014) Vitamin D status in chronic dialysis patients with depression: a prospective study. BMC Psychiatry14 (125): 1-7. 